This copy is author's original pre-print version and may slightly differ from the official published version.

Full citation:

Harkonen, J., Belt, P., Mottonen, M., Kess, P. and Haapasalo, H. (2009) 'Analysing telecom companies using the Toyota NPD model', International Journal of Mobile Communications, Vol. 7, No.5, pp. 544-561.

DOI: 10.1504/IJMC.2009.024392

\title{
Analysing telecom companies using the Toyota NPD model
}

\section{Janne Harkonen*, Pekka Belt, Matti Mottonen, Pekka Kess and Harri Haapasalo}

Department of Industrial Engineering and Management, University of Oulu, Finland, P.O. Box 4610,

FI-90014 University of Oulu, Finland

E-mail: janne.harkonen@oulu.fi

E-mail: pekka.belt@oulu.fi

E-mail: matti.mottonen@oulu.fi

E-mail: pekka.kess@oulu.fi

E-mail: harri.haapasalo@oulu.fi

*Corresponding author

\begin{abstract}
The telecom sector is facing great challenges in its new product development (NPD) as products are getting increasingly complicated, and customer segments more fragmented. This study uses a benchmark from the automotive industry to obtain ideas for improving NPD and requirements management in the telecom sector. Toyota was chosen as the benchmark as the automotive industry has been a large volume, mature and competitive business sector, and as Toyota has been successful in streamlining its business processes, and in meeting customer needs. The study clarifies the similarities and the main differences between interviewed telecom companies and NPD practices at Toyota.
\end{abstract}

Keywords: requirements management; benchmarking; NPD; lean; product development; Toyota; telecom; mobile communications. 


\section{Introduction}

The telecom industry has grown rapidly during the last decades, and devices, such as mobile phones have become a commodity. The pace of new product introductions has increased tremendously. In order to survive in tough competition companies must be able to create high-quality products that fulfil the desires and needs of their customers; technical superiority is not enough for companies to succeed. Severe global competition forces them to reduce costs, shorten development times and production lead-times (e.g. Seetharaman et al., 2007). An efficient new product development (NPD) process is therefore a necessity. (e.g. Gupta et al., 2007; Pisano and Wheelwright 1995; Nonaka and Takeuchi, 1995; Gressgard and Stensaker, 2006; Drejer, 2008).

Products being more complicated than ever, and customer segments more fragmented, requirements management and verification and validation $(\mathrm{V} \& \mathrm{~V})$ have become a bottleneck for product development and production. Requirements for products are set by customers, standards and technical constraints. Identifying and communicating customer needs and expectations into requirements have been emphasised as a challenge for the early product development (e.g. Engelbrektsson and Soderman, 2004; Hsieh and Chen, 2005). Requirements management, including V\&V is estimated to be responsible for over $50 \%$ of the NPD costs. (e.g. Engel \& Last, 2007; Gilb, 2005; Belt et al., 2008; Perttula, 2007; Murray, 2007).

Despite of being at the pinnacle of technological development in many areas, the telecom industry is, in many respects, an immature sector, and benchmarking with other sectors, such as the automotive industry, can be beneficial. The car industry has been a large and competitive sector for decades, and their NPD processes have been streamlined and developed to a very high level of productivity and performance. Toyota has been a successful company in the automotive business, creating quality cars, faster and with a greater profit than its competitors (e.g. Chin et al., 2008). It also launches more new products annually than most of its competitors. Toyota has been effective also in managing requirements, and customer needs, making their example especially interesting for this study. Another motivation for using Toyota as a source for ideas is that their procedures are well documented in the literature. (e.g. Morgan and Liker, 2006; Ford and Sobek, 2005)

This study analyses how telecom companies could improve their NPD activities, and their requirements management. Toyota's NPD (TNPD) is used as a benchmarking tool for analysing the existing practices. Morgan and Liker (2006) have described TNDP to include thirteen principles, covering processes, people, and technological issues.

The above mentioned can be condensed into the research question:

RQ What type of similarities and differences are there between the current state of NPD, and requirements management in telecom companies, and Toyota NPD practices?

This study addresses the research question in a qualitative manner both, through literature and industry interviews.

\section{Improving NPD process}

Performance of new product development activities is increasingly important. The efficiency and effectiveness of these activities are seen as one of the factors determining a firm's competitive advantage, and its very survival (e.g. Godener and Soderquist, 2004; 
Meyer et al., 1997; Khan et al., 2007; Loch et al., 1996; Caputo and Pelagagge, 2008). It is seen vital for product innovation to link technological competence, engineering and process know-how, as well as knowledge of customer needs (e.g. Su et al., 2007; Lee, 2008).

Generating products faster than competitors does not always equal to commercial success, and forcing rapid development in an environment of high technological and market uncertainty may produce failure (e.g. Meyer and Utterback 1995; Griffin, 1993). Ford and Sobek (2005) prove how converging development efforts too quickly, or too slowly, degrades project value. To avoid failure, before trying to accelerate product development, NPD process must be streamlined through simplicity and efficiency.

The development of lean NDP processes typically starts with creating efficient processes, after which the emphasis is on shortening development times, and on timing of different actions. According to Blog (2007) the real benefits of lean NPD come from creating a flow. Also, for more complex environments, it is seen to be the functions other than production that offer relevant solutions.

\subsection{Requirements management}

Requirements for products are set by customers, standards and technical constraints. Identifying and communicating customer needs and expectations into requirements have been emphasised as a challenge for product development (e.g. Engelbrektsson and Soderman, 2004; Zeidler et al., 2008; Dawidson and Karlsson, 2005; Ojiako et al., 2008). Figure 1 illustrates requirements within the NPD process.

Figure 1. Requirements within the NPD process

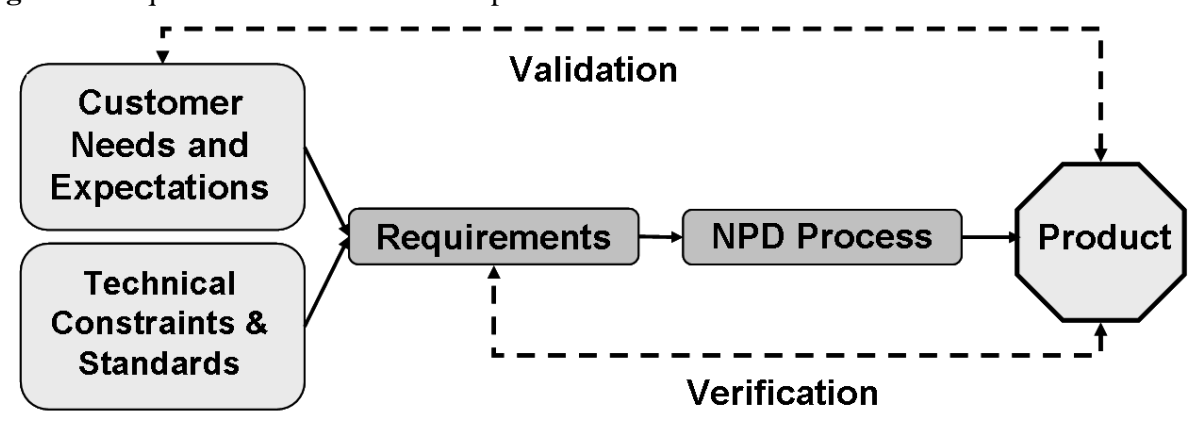

Obtaining the relevant understanding to be reflected as requirements is of vital importance. However, communicating the requirements within the company and to its suppliers has been identified as a challenge (e.g. Matson and Matson, 2007; Sinha et al., 2006). This is where different types of product plans, sketches, simulations and different type of physical representations can act as tools for communication (e.g. Wheelwright and Clark 1994; Ulrich and Eppinger 1995). Managing the relevant information is seen to have implications for new product performance (Rui et al., 2008). Companies do not necessarily have experienced requirements engineers at their service, yet hundreds of methods have been constructed to address the problem of acquiring, analysing, and communicating requirements (e.g. Fricker et al., 2006; Misra et al., 2008).

Companies need ways to prioritise technical and customer requirements (e.g. Liu et al., 2006). These requirements also include the ones set by standards (e.g. Darabi et al., 2005). The requirements set, usually continue developing until the product launch, and must therefore be managed carefully. During the process, the management requires understanding over the state of meeting the requirements. 
Defining and agreeing product requirements is especially important when the design activities and production are dispersed. It can be difficult to have a shared understanding over priorities, causing specifications to contain ambiguities in describing the requirements (e.g. Kerr et al., 2006).

\subsection{Toyota new product development}

Toyota has been successful in the automotive business with harsh international competition. Quality and efficient production have been the cornerstones of Toyota's achievements, but to an ever greater extent, also successful product development has greatly contributed to their success. Several authors have studied Toyota and its NPD (Morgan and Liker, 2006; Kamath and Liker, 1994; Ward et al., 1995; Vassilakis, 1998; Sobek et al., 1999; Liker, 2004; Hong et al., 2004; Hines et al., 2006), making TNPD well documented. Toyota's development process is said to look expensive, clumsy and inefficient to outsiders, yet they are among the fastest product developers in their industry (e.g. Radeka, 2007; Vassilakis, 1998; Oakley, 1997; Ward et al., 1995).

Higher customer orientation, cross-functional integration, and new product team proficiency have been identified as the success factors of Japanese NPD. The NPD success is seen to come as a result of focusing efforts on these areas rather than across a diffused set of factors. (Im et al., 2003; Brown and Maylor, 2003; Ibusuki and Kaminski, 2007).

Toyota's product development is seen to be managed as a system. The key aspects are seen to include the harmony of different mechanisms, and knowledge being shared across projects (Haque and James-Moore, 2004; Dyer and Nobeoka, 2000; Chow et al., 2007). Factors identified as keys to the Toyota's NPD system include delayed decision making, knowledge management, and set-based concurrent engineering (SBCE) (see, e.g. Hines et al., 2006; Morgan and Liker, 2006; Appleton and Short, 2008; Liker, 2004; Sobek et al., 1999; Ward et al., 1995; Kamath and Liker, 1994).

Toyota's set-based approach of intentionally delaying alternative selection is explained as a real options approach to product development management (Ford and Sobek, 2005; Yang et al., 2004). Real options in this case include the ownership, the value source, complexity, and the availability of an option. SBCE utilised by Toyota includes different actors working on rough-cut designs within defined frame, or envelopes, that they have means to work within. This type of approach aids to avoid over-the-wall designs, where different departments do not sufficiently support the realities of other stages facing the design later in the process (Hines et al., 2006).

There are indications of Toyota employees being involved in learning practices, representing a good strategy for managing continuous change that is necessary for successful new product introductions. (Fuchs, 2007; Chang and Cho, 2008).

Morgan and Liker (2006) have presented TNPD to include: 1) processes, 2) people, and 3) tools and technology, which are seen to interrelate, and to be interdependent. TNPD has been further divided into 13 principles, see Figure 2. These thirteen principles are the basis utilised for further analyses in this study. 
Figure 2. The principles of TNPD

Processes
(1) Establish Customer-Defined Value to Separate Value-Added from Waste
(2) Front-Load the PD Process to Explore Alternatives Thoroughly
(3) Create a Levelled Product Development Process Flow
(4) Utilise Rigorous Standardisation to Reduce Variation and Create
Flexibility and Predictable Outcomes
People
(5) Create a Chief Engineer System to Lead Development from Start to Finish
(6) Organise to Balance Functional Expertise and Cross-Functional Integration
(7) Develop Towering Technical Competence in All Engineers
(8) Fully Integrate Suppliers into the Product Development System
(9) Build in Learning and Continuous Improvement
(10) Build a Culture to Support Excellence and Relentless Improvement
Tools \& Technology
(11) Adapt Technology to Fit Your People and Processes
(12) Align Your Organisation through Simple, Visual Communication
(13) Use Powerful Tools for Standardisation and Organisational Learning

Processes sub-system includes defining the factors creating value to customers, whilst everything else is eliminated as waste (Faisal et al., 2006). The goal is to create unambiguous, lean NPD process, where all the functions are synchronised, and the use of resources is flexible. Additionally, the NPD process is front-loaded by emphasising the early activities (e.g. Veryzer and de Mozota, 2005; Binder et al., 2008). A number of alternative solutions is studied and developed, delaying final technological decisions. Standardisation is utilised for reducing variation, and to ease the common understanding.

People sub-system is characterised by a matrix organisation, where the functional dimension is emphasised. For example, Toyota uses experienced, senior people with strong engineering background, chief engineers (CE), in a co-ordinating role for crossfunctional dimension (e.g. Haque and James-Moore, 2004). Also, the technical competence of employees is both highly appreciated, and systematically developed, including active career planning. In addition, the suppliers are fully integrated into the Toyota organisation. There is a great emphasis on continuous improvement in all actions.

Tools \& technology sub-system includes a penetrating fit-for-purpose mentality for acquiring technology, and technology is not admired as such. Technologies must support people and processes, and act as means for efficiency. There is a strive for simplifying and visualising all the information at Toyota, and adapting the information into the most suitable format for different users.

For detailed description of each the thirteen principles, please see Morgan and Liker (2006). It must be noted, however, that following TNPD blindly is not an optimal approach as business sectors are different (e.g. Rosemann, 2006). TNPD has also received critical analysis. (e.g. Oliver et al., 2004; Radeka 2007). 


\section{Empirical study}

\subsection{The research process}

The research process is described in Figure 3. The Toyota new product development process was analysed by using existing literature as a source as summarised in the chapter 2.2. Industrial interviews were carried out in the telecom sector, to clarify the similarities and differences between the Toyota NPD, and the practices of telecom companies. Finally, results were analysed and summarised. The results of the analysis are presented in the section 3.2 results and analysis.

Figure 3 the research process

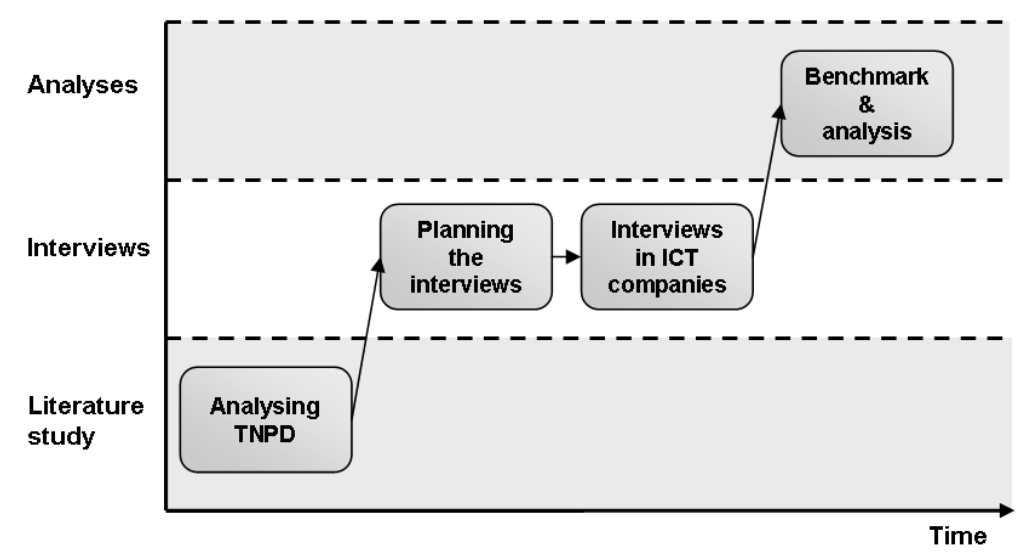

The study consisted of fifty three interviews, and eleven companies, in which at least three people were interviewed. The interviews comprised a representation from different phases of the new product development process. The interviews were conducted informally, in a qualitative manner, allowing the interviewees to explain and clarify the cases and topics as entities.

All the individual interviews were analysed separately by using TNPD as a tool, in order to find the similarities and discrepancies between the model and the studied companies. The analyses were divided into thirteen principles listed in Figure 2.

The companies that participated in the interviews represent different phases of telecom's supply chain. The first company type is the 'device' manufacturers that sell their products globally. These companies provide products for both business-to-customer and for business-to-business markets. The second type of companies can be seen as subcontractors, whose products are inputs into the first category. The third category is companies who provide comprehensive services, including equipment, know-how and consulting services. Therefore, these interviews represent the NPD activities in a versatile manner and provide understanding over managing diverse issues.

The participants interviewed were selected carefully on the basis of their professional background and expertise. Selected participants hold responsible positions related to new product development. The job titles of the respondents include: CEO, Competence Area Manager, Development manager, Director of Quality and engineering, Director of R\&D, Director of Technology, Engineering Manager, Product manager, Product Development Manager, Production manager, Project manager, Quality Controller, Quality manager, 
Senior Test Manager, Senior design engineer, Senior development engineer, Senior specialist, Team leader (hardware), Team leader (software). The selected participants are among the top-professionals in the telecom sector.

\subsection{Results and analysis}

The interview material was analysed by using TNPD (see also Figure 2). The interviewee comments were examined against the thirteen principles covering processes, people, and tools \& technology. The results obtained were then analysed as entities, resulting in conclusions of the current state of telecommunications industry, and indications on similarities and differences against TNPD. The results of the analyses for each of the thirteen Toyota's principles are presented below.

\subsubsection{Process}

\section{(1) Establish Customer-Defined Value to Separate Value-Added from Waste}

The studied companies clearly indicate processes being in place for addressing customer needs. Business-to-business companies, in particular, seem to have intimate relationships with their customers, and their product development is strongly customer-driven. The studied companies do not, however, widely follow the lean principles in developing their processes through the exclusion of all non-value adding activities. There are only isolated cases where systematic minimisation of non-value adding activities can be found. Additionally, employees in many of the studied companies seem to think that it is only the higher level managers who analyse customer-value and initiate related actions. Also, in the studied companies the appreciation of internal customers is especially meagre.

\section{(2) Front-Load the PD Process to Explore Alternatives Thoroughly}

All the studied companies indicate intentions, and actions, emphasising the early part of the NPD process. The product development in the studied companies is strongly platform-based, aiming towards generic solutions. The greatest challenge seems to be finding platforms that can fulfil the needs of later NPD phases, and understanding the constraints of these internal customers.

Preparing for technological uncertainties through analysing several alternatives is weak in most of the interviewed companies, compared to TNPD. The companies seem to fix their technological solutions early, and do not usually explore parallel options. There was evidence of only isolated cases utilising the delayed decision-making tactics similar to Toyota. In fact, it was only the globally significant companies who would even attempt delayed decision making and parallel development.

\section{(3) Create a Levelled Product Development Process Flow}

The interviewed companies seem to be incapable of optimally removing overlapping work. This seems to be especially true for separate functions, such as testing. Tangible actions for rationalising testing seem to be sporadic. On the other hand, companies do utilise fault statistics for developing their processes.

The flexibility targets set for product development are generally addressed by flexible resource utilisation, and investing in employees' competence development. A significant challenge for the studied companies seems to be identifying the real needs of internal customers, making it difficult to optimally level their NPD processes. Most of the 
interviewed companies seem to, however, understand the need for coordinators, to link the NPD phases.

\section{(4) Utilise Rigorous Standardisation to Reduce Variation and Create Flexibility and Predictable Outcomes}

There are visible ambitions for standardising technologies, and technical solutions, in the studied companies. However, there is not equally strong evidence on standardisation of product development processes, and requirements management. Also, standardisation of people skill-set is not brought up as strongly in the studied companies as in TNPD. The companies seem to appreciate human competences, but standardised career paths are not a part of systematic company policies.

\subsubsection{People}

\section{(5) Create a Chief Engineer System to Lead Development from Start to Finish}

Roles similar Toyota's Chief Engineer are not found among the studied companies. Typically, the same functions are managed by using programme/product managers responsible for product development. There seem to be similarities in the roles Toyota's $\mathrm{CE}$ and the product management of the studied companies. However, none of the interviewees named them directly as the system integrators for the NPD process. Programme managers are identified to have a strong marketing emphasis in contrast to Toyota where the CE has engineering background and can therefore, cope with technical issues in addition to managerial duties. Noteworthy is that the CEs are experienced people with and the role is highly ranked, while product managers in the studied companies are typically much younger.

\section{(6) Organise to Balance Functional Expertise and Cross-Functional Integration}

The interviews indicate balancing the development of functional expertise and crossfunctional integration being challenging for the companies. It is clearly visible how in small companies, the success of product development projects overruns the development of functional expertise. In larger and more developed companies, the solutions seem more similar to the Toyota way. It is identified easier for these larger ones to respect the functional expertise without having to divide the experts individually into projects. Practising expertise as a team entity is brought up as helpful for maintaining and developing the collective competence. Cross-functional integration, typical to Toyota, is attempted to address in the interviewed companies by organising internal meetings and seminars on a regular basis.

\section{(7) Develop Towering Technical Competence in All Engineers}

The competence development, and career paths, of personnel are managed at the company level at Toyota. In the studied companies, the employees themselves are, in contrast, seen as the engines of their own career development. Noteworthy is that career planning is not systematically considered at company level in the interviewed organisations. In small rapidly growing companies, low ranking managers are typically promoted from the operational level according to urgent needs, and quick career changes are frequent. Even the larger companies were not identified to have systematic career path planning; rather the changes in individual roles seem to be reactions to prevailing needs. 
Technical competences are considered very important for business success in all the interviewed companies, and attention is paid for their development. It is typically, however, up to individuals to take the responsibility for their own competence development. There are only isolated cases, where potential individual are offered mentoring to develop their competences, and given possibilities for advancing towards more demanding positions.

\section{(8) Fully Integrate Suppliers into the Product Development System}

Integration of outsourced activities into company processes seem to be shallower in the studied companies than at Toyota. In many cases, the communication is managed merely by sales, marketing and purchasing personnel, especially in smaller companies. On the other hand, there are small subcontractors where practically all employees, are in a way or other, directly in cooperation with clients.

According to the interviewees, the subcontractor and their customers have quite often common data systems for information sharing. In some cases, instructors and other personnel from the customer company are sent to train the subcontractor's employees.

During product development phase subcontractors employees are identified to be in close cooperation with the client company. The communication between the companies is, however, considered challenging. The study also revealed cases where the larger client is pushing the subcontractors price-wise using their bargaining power, making the longterm cooperation difficult unless the development is supported by the client.

\section{(9) Build in Learning and Continuous Improvement}

According to the interviewees, there are some practices in the companies for continuous learning and improvement. For example, after a project is finished, meetings and reviews are organised in order to find areas for development. More in-depth culture for systematic, continuous improvement cannot be identified for the interviewed companies, in the same way as emphasised in TNPD. In the interviewed companies, learning is typically based on previous experiences without deep root-cause analyses. Transferring and utilising tacit knowledge are attempted, in the interviewed companies, via mentoring, and knowing people personally. However, systematic ways of transferring this type of knowledge cannot be identified.

\section{(10) Build a Culture to Support Excellence and Relentless Improvement}

The interviewees indicated a strong strive for developing technologically advanced, high quality products, and improving through learning from the mistakes, and previous defects. The culture among the interviewed companies is idolising technology, while the customer orientation and strive for efficiency is not as strong as at Toyota. There are cases where continuous improvement was not internalised by all the employees. In some companies, the number of defects influences the compensation management.

\subsubsection{Tools \& Technology}

\section{(11) Adapt Technology to Fit Your People and Processes}

The interviewees indicate that the companies have a 'push' attitude on technological issues, potentially over-addressing the meaning of the latest technology. The most advanced of the companies utilise a 'pull' philosophy where real needs guide their technology acquisitions, to optimally support company processes and actual work of the 
personnel. The weaker companies do not see this as a critical success factor requiring considerable attention. In some cases, follower strategy is applied, and those technologies utilised by others are considered interesting.

\section{(12) Align Your Organisation through Simple, Visual Communication}

The interviewees indicate that the companies do not sufficiently assure that the information is timely, in a suitable format, or its adaptation to different users. There seems to be an overload of data from numerous sources, thus it is not adequately analysed. There is no evidence on having roles similar to Toyota's CE for filtering information. The interviewees have not acknowledged the need for simple visual communication. The interviewed companies do not have a culture of broad discussions aiming for consensus, but managers experience making decisions being a part of their role.

\section{(13) Use Powerful Tools for Standardisation and Organisational Learning}

In most of the interviewed companies, especially in the larger ones, databases are utilised for a guiding role for developing products and processes. There seem to be vast variation in the success rate in utilising this data, one of the biggest challenges being the amount of information. There is no clear evidence of categorisation of the information based on its relevance, neither who would benefit of the information the most and in which format. The need for further processing the collected data is well understood, but proper solutions have not been found. Although there are good examples of more tangible data utilisation, such as giving feedback for programmers on the amount of defects in the field, so the programmer could learn from this experience.

\subsubsection{Synthesis}

In this study, product development processes and requirements management of telecom companies are analysed by using TNPD as a benchmarking tool. The realisation of the principles of TNPD is analysed in telecom companies, covering different actors within their supply chain. The motivation is to find potential viewpoints for the telecom companies to learn from the practices of a mature business sector, and those of a successful company. Table 1 summarises the key observations on the interviewed companies' compliance against TNPD, highlighting the main similarities and differences.

Table 1. Main similarities and differences between TNPD and the current state in the interviewed telecom companies. The numbers refer to the respective principles in TNPD.

\begin{tabular}{|c|c|c|}
\hline & Similarities & Differences \\
\hline$\overline{(1)}$ & $\begin{array}{l}\text { Identifying customer needs is } \\
\text { emphasised }\end{array}$ & $\begin{array}{l}\text { Lean principles are not followed widely in } \\
\text { telecom }\end{array}$ \\
\hline (2) & $\begin{array}{l}\text { Front loading NPD through platform } \\
\text { based development }\end{array}$ & $\begin{array}{l}\text { Multiple options and technologies are } \\
\text { only considered in larger companies }\end{array}$ \\
\hline (3) & $\begin{array}{l}\text { The importance of removing } \\
\text { overlapping work is identified }\end{array}$ & $\begin{array}{l}\text { Inadequate understanding of the } \\
\text { requirements set by internal customers is } \\
\text { a challenge }\end{array}$ \\
\hline (4) & $\begin{array}{l}\text { Standardising technology is a strong } \\
\text { point }\end{array}$ & $\begin{array}{l}\text { Standardising processes, but especially } \\
\text { people skill-set lesser }\end{array}$ \\
\hline
\end{tabular}


(5) Programme management leads the development

(6) Large companies do balance functional expertise and crossfunctional integration

(7) Technical know-how is acknowledged fundamental

(8) Common databases with suppliers are utilised for information exchange

(9) Strive to learn from previous faults

(10) Strive for excellence

(11) At best procuring technology is pullbased

(12) Need for rationalising information is acknowledged. Strive for personal feedback.

(13) Knowledge is accumulated and stored into databases
A person similar to Toyota's Chief
Engineer does not exist

Small companies do not especially

consider the organisational structure

Competence development directed by individuals, not the company

Supplier integration could be stronger, and the interface between supplier and the client more vacillating

Practices for transferring tacit knowledge have room for improvement

Continuous improvement not systematic

Time constraints and lack of resources leading to inadequate consideration of the appropriateness of procured technology

Need for simple visual communication not profoundly acknowledged.

No adequate consideration of the real needs for stored data

The study shows how the interviewed telecom companies have a clear aim to shift the emphasis of their product development processes towards earlier phases, the same way as highlighted in TNPD. Especially platform-based product development is strongly applied in order to achieve this shift. However, the strategy of using parallel alternatives, and technologies, is not widely applied. On the contrary, technological solutions are typically fixed, in the interviewed companies, as early as possible. The study did not find evidence on any real ambitions for lean culture, so that the companies would systematically reduce all non-value adding activities and overlapping work. Even though the companies do strive for efficiency, profound lean culture could not be identified.

All the interviewed companies recognise the importance of personnel competencies and the necessity for developing them in order to succeed in severe competition. However, there seem to be significant discrepancies in developing competencies, among the studied companies and Toyota. The development of personnel competencies are strongly company driven at Toyota, where career paths are planned, and realised in practice. The interviewed companies seem to be missing systematic, organisation led, career path planning for competence development. However, there are indications of mentoring and organised job rotation, but only for key employees. It is typical for the interviewed companies that the competence development is the responsibility of individual employees themselves.

Roles similar to Toyota's Chief Engineer do not exist in the interviewed telecom companies for guiding the entire development process. Toyota utilises CEs to address the challenges of cross-functional integration typical in matrix organisations. Programme management type arrangements are in place in the interviewed companies for the development process integration. However, seniority, technical focus, and penetrating focus on customer requirements are not emphasised as strongly as at Toyota. 
One of the greatest differences is the interviewed companies admiring the latest technology, and an emphasised strive for technological superiority. Toyota, on the other hand, emphasises efficiency, quality and customer-orientation, so that technology is not seen as value as such, but is required to add value. At Toyota technologies are acquired to fit a purpose, on a pull-principle. Only few of the larger interviewed companies are analysing what the business processes and employees really need, when considering technology acquisitions.

Another challenge identified in the telecom companies is processing of data gathered from products, and from customers. There is not adequate enough consideration of what information, and in which format, is required by different employees at different levels. In addition, visualisation of the most important information is almost non-existent.

\section{Managerial implications}

In order to maintain their competitiveness, companies are constantly renewing themselves. Successful, and efficient, product development is one of the key functions, especially in today's telecom sector. Companies require fresh ideas for renewal, also from the outside world.

The automotive industry has been a large volume, competitive business sector. The business volume of the telecommunications sector has been much smaller, but has recently experienced an enormous growth. Benchmarking with the automotive industry is useful for telecom to gain fresh perspectives, even though following TNPD blindly does not make sense as there are differences in these business sectors: in profit margins, timeframes for platforms, and so on.

Toyota's philosophy is hierarchical, where the customer perspective and requirements management come first. At the second level, internal efficiency and business processes are streamlined to optimally serve the customer orientation. The required personnel competences and their continuous improvement are also considered at this level. At the third level, technology has a role of merely serving processes and personnel competences for achieving the higher level goals.

Managing requirements has become a bottleneck for product development in the telecom sector. Toyota seems to have effective means to cope with this challenge throughout all their operations. This is why it is beneficial to study how telecom can learn from Toyota. According to the interviews, the format and flow of information are deficient in the telecom sector. The vast amount of data is not analysed, the relevant information has not been identified, and tailored, for each employee in a simple, visual manner. This is influenced by the internal customers not being adequately acknowledged. Toyota has addressed its cross-functional integration with e.g. chief engineer arrangement that eases the information flow and better serves internal customers. The CEs are experienced and highly respected managers in contrast to similar issues being managed by junior programme managers in telecom.

According to the interviews, the largest and most advanced companies are already applying similar principles as Toyota to some degree, even though they are not necessarily aware of the model. It might be worthwhile for companies to analyse the applicability of this type of philosophies more systematically.

Although, Toyota's product development system is very effective for Toyota, it is unrealistic for companies to start following a new model directly. TNPD is not a straightforward action plan, and the thirteen principles are strongly interdependent making it laborious to apply. Even within Toyota, to teach the lean product development to new employees globally is a challenge (Morgan and Liker, 2006). 
Based on the analysis in this study, it seems that the TNPD model is a suitable source for ideas for large infrastructure and gadget suppliers of the telecom sector. Smaller companies, as well as service providers, can probably utilise the model better indirectly, for understanding their customers, and other important players in their field, and directly only in selected issues, such as simple visual communication, or delayed decision making. However, the suitability issues to different type of companies should be studied more thoroughly.

\section{Conclusions}

Businesses must constantly develop their activities in order to maintain and improve their competitiveness. Benchmarking other companies, and other business sectors, is a method used for gaining new ideas. This study utilises TNPD as an analysis tool for obtaining fresh views for NPD, and requirements management, for Scandinavian telecom companies.

The analyses indicate the largest, and more advanced, companies applying similar principles to Toyota, to a greater extent than their subcontractors, and smaller ones in general. Nevertheless, all the companies used at least some of the Toyota's principles. Such a profound lean culture, as at Toyota, could not be identified in any of the interviewed companies.

Significant differences between the interviewed companies and TNPD could be identified; some of these discrepancies are potential sources for improvement ideas, for the telecom companies. The similarities and differences are summarised in Table 1 . The potential considerations for telecom, identified in the study, include the role of chief engineer in managing NPD, parallel development and postponed decision making, and company led competence development.

The challenge of combining customer needs \& requirements, functional expertise \& cross-functional integration in effective NPD is addressed by Toyota using the CE concept. The programme manager type solutions typically used by telecom companies are not similarly profound for addressing these issues as Toyota's CE.

Uncertainty linked to product development may be eased by utilising parallel development and delayed decision making similar to Toyota's set-based development. Requirements typically change during the NPD projects causing great challenges for requirements management. However, parallel development and delayed decision making, do not necessarily fit all the companies, yet are worth consideration.

In all the interviewed companies, personnel competencies are considered important. Nevertheless, often the individual employees seem to be themselves responsible for the development of these competences. At Toyota systematic competence development and career planning are company driven.

The purpose of this study is to find ideas for the telecom companies to develop their NPD practices, and not to make an all-inclusive analysis on differences between Toyota and the interviewed companies. TNPD is very functional for Toyota, however, it is unrealistic for companies to start following their model strictly. TNPD is not a straightforward action plan, making it challenging to apply. This research is qualitative by nature, and its purpose is to find ideas for telecom companies for developing their NPD and requirements management practices. The intention is not to make an allinclusive analysis. Although, the participating companies are analysed by interviewing several people per company, conducting a more comprehensive analysis might give slightly different results. 
Areas for further study include analysing, in more detail, the best performing telecom companies, utilising principles similar to Toyota. This is to allow other telecom companies to learn from their own business sector's representative on how to apply the lucrative aspects of lean NPD. Also, the suitability of TNPD to different type of telecom companies should be studied more thoroughly.

\section{References}

Appleton, E.A. and Short, T.D. (2008) 'New product development 'according to Hoyle': part 1 the analogy', Journal of Engineering Design, Vol. 19, No. 3, pp. 285-298.

Belt, P., Harkonen, J., Mottonen, M., Kess, P. and Haapasalo, H. (2008) 'Improving the efficiency of verification and validation', International Journal of Services and Standards, Vol. 4, No. 2, pp. 150-166.

Binder, M., Gust, P. and Clegg, B. (2008) 'The importance of collaborative frontloading in automotive supply networks', Journal of Manufacturing Technology Management, Vol. 19, No. 3, pp. 315-331.

Blog, I (2007) 'Rethinking lean NPD: A distorted view of lean product development, Strategic Direction, Volume 23, Number 10, pp. 32-34.

Brown, S. and Maylor, H. (2003) 'Strategic resonant firms, mass producers, big fish \& flat liners: a study of policies, practices \& performance in innovation', Technovation, Vol. 25, No. 4, pp. 307-319.

Caputo, A.C. and Pelagagge, P.M. (2008) 'Effects of product design on assembly lines performances: A concurrent engineering approach', Industrial Management \& Data Systems, Vol. 108, No. 6, pp. 726-749.

Chang, D.R. and Cho, H. (2008) 'Organizational memory influences new product success', Journal of Business Research, Vol. 61, No. 1, pp. 13-23.

Chin, K.-S., Chan, B.L. and Lam, P.-K. (2008) 'Identifying and prioritizing critical success factors for coopetition strategy', Industrial Management \& Data Systems, Vol. 108, No. 4, pp. 437454.

Chow, H.K.H., Choy, K.L. and Lee, W.B. (2007) 'Knowledge management approach in build-toorder supply chains', Industrial Management \& Data Systems, Vol. 107, No. 6, pp. 882-919.

Darabi, H., Chiu, J., Khorram, S., Hea J.K., Zhimin Z. Hung-Ming C., Ibrahim, B., Geronaga, E., Tran, L.H. and Rofougaran, A. (2005) 'A dual-mode $802.11 \mathrm{~b} / \mathrm{bluetooth}$ radio in $0.35-/ \mathrm{spl}$ mu/m CMOS', IEEE Journal of Solid-State Circuits, Vol. 40, No. 3, pp. 698- 706.

Dawidson, O.M. and Karlsson, M.G. (2005) 'Towards a framework supporting the management of product boundaries: a study of the new situation experienced by Ericsson Mobile Platforms', International Journal of Mobile Communications, Vol. 3, No. 1, pp. 49-65.

Drejer, A. (2008), 'Are you innovative enough?', International Journal of Innovation and Learning, Vol. 5 No. 1, pp. 1-17.

Dyer, J.H. and Nobeoka, K. (2000) 'Creating and managing a high-performance knowledge-sharing network: the Toyota case', Strategic Management, Vol. 21 No. 3, pp. 345-367.

Engel, M. and Last, M. (2007) 'Modeling software testing costs and risks using fuzzy logic paradigm', The Journal of Systems \& Software, 20079 (3), pp. 259-280.

Engelbrektsson, P. and Soderman, M. (2004) 'The use and perception of methods and product representations in product development: A survey of Swedish industry', Journal of Engineering Design, Vol. 15, No. 2, pp. 141 - 154.

Faisal, M.N., Banwet, D.K. and Shankar, R. (2006) 'Mapping supply chains on risk and customer sensitivity dimensions', Industrial Management \& Data Systems, Vol. 106, No. 6, pp. 878895. 
Ford, D.N. and Sobek, D.K. II (2005) 'Adapting real options to new product development by modeling the second Toyota paradox', IEEE Transactions on Engineering Management, Vol. 52, No. 2, pp. 175 - 185.

Fricker, S., Glinz, M. and Kolb, P. (2006) 'A Case Study on Overcoming the Requirements Tar Pit', Journal of Universal Knowledge Management, vol. 1, no. 2, pp. 85-98.

Fuchs, B. (2007) 'Learning from Toyota: how action learning can foster competitive advantage in new product development (NPD)', Action Learning: Research and Practice, Vol. 4, No. 1, pp. $25-43$.

Gilb, T. (2005) 'Competitive Engineering: A Handbook for Systems Engineering, Requirements Engineering, and Software Engineering Using Planguage', pp.480.

Godener, A. and Soderquist, K.E. (2004) 'Use and impact of performance measurement results in R\&D and NPD: an exploratory study', R\&D Management, Vol. 34, No. 2, pp. 191-219.

Gressgard, L.J. and Stensaker, I. (2006) 'The mobile service industry: strategic challenges and future business models', International Journal of Mobile Communications, Vol. 4, No. 5, pp. 509-531.

Griffin, A. (1993) 'Metrics for Measuring Product Development Cycle Time', Journal of Product Innovation Management, Vol. 10, No. 2, pp. 112-125.

Gupta, A., Pawara, K.S. and Smart, P. (2007) 'New product development in the pharmaceutical and telecommunication industries: A comparative study', International Journal of Production Economics, Vol. 106, No. 1, pp. 41-60.

Haque, B. and James-Moore, M. (2004) 'Applying lean thinking to new product introduction', Journal of Engineering Design, Vol. 15, No. 1, pp. 1-31.

Hines, P., Francis, M. and Found, P. (2006) 'Towards lean product lifecycle management: A framework for new product development', Journal of Manufacturing Technology Management, Vol. 17, No.7, pp. 866-887.

Hong, P., Doll, W.J., Nahm, A.Y. and Li, X. (2004) 'Knowledge sharing in integrated product development, European Journal of Innovation Management, Vol. 7, No. 2, pp. 102 - 112.

Hsieh, L-F., and Chen, S.K., 2005. Incorporating voice of the consumer: does it really work? , Industrial Management \& Data Systems, Vol. 105, No. 6, pp. 769-785.

Ibusuki, U. and Kaminski, P.C. (2007) 'Product development process with focus on value engineering and target-costing: A case study in an automotive company', International Journal of Production Economics, Vol. 105, No. 2, pp. 459-474.

Im, S., Nakata, C., Park, H. and Ha, Y.W. (2003) 'Determinants of Korean and Japanese New Product Performance: An Inter-Relational and Process View', Journal of International Marketing, Vol. 11, No. 4, pp. 81-112.

Kamath, R. and Liker, J. (1994), 'A second look at Japanese product development', Harvard Business Review, Vol.72, No. 6, pp. 154-170.

Kerr, C.I.V., Roy, R. and Sackett, P.J. (2006) 'Requirements management: an enabler for concurrent engineering in the automotive industry ', International Journal of Production Research, Vol. 44, No. 9, pp. 1703 - 1717.

Khan, Z., Bali, R.K. and Wickramasingh, N. (2007), 'Identifying the need for world class manufacturing and best practice for SMEs in the UK', International Journal of Management and Enterprise Development, Vol. 4 No. 4, pp. 428-440.

Lee, L.T.-S. (2008) 'The effects of team reflexivity and innovativeness on new product development performance', Industrial Management \& Data Systems, Vol. 108, No. 4, pp. 548569.

Liker, J. (2004) ‘Toyota Way', McGraw-Hill, New York, pp.350.

Liu, F., Noguchi, K., Dhungana, A., Srirangam A.V.V.N.S.N. and Inuganti, P. (2006) 'A quantitative approach for setting technical targets based on impact analysis in software quality function deployment (SQFD), Software Quality Journal, Vol. 14, No. 2, pp. 113-134. 
Loch, C., Stein, L. and Terwiesch, C. (1996) 'Measuring Development Performance in the Electronics Industry', Journal of Product Innovation Management, Vol. 13, No. 1, pp. 3-20.

Matson, J.E. and Matson, J.O. (2007) 'Just-in-time implementation issues among automotive suppliers in the southern USA', Supply Chain Management: An International Journal, Vol. 12, No. 6, pp. 432-443.

Meyer, M.H., Tertzakian, P. and Utterback, J.M. (1997), 'Metrics for Managing Research and Development in the Context of the Product Family', Management Science, Vol. 43, No. 1, pp. 88-111.

Meyer, M.H. and Utterback, J.M. (1995) 'Product development cycle time and commercial success' IEEE Transactions on Engineering Management, Vol. 42, No.4, pp. 297-304.

Misra, S.C., Kumar, U. and Kumar, V. (2008) 'Modelling strategic actor relationships for risk management in organizations undergoing business process reengineering due to information systems adoption', Business Process Management Journal, Vol. 14, No. 1, pp. 65-84.

Morgan, J.M. and Liker, J.K. (2006) 'The Toyota product development system: integrating people, process, and technology', Productivity Press, pp. 377.

Murray, R.M. (2007) 'Recent Research in Cooperative Control of Multivehicle Systems', Journal of Dynamic Systems, Measurement, and Control, Vol. 129, No. 5, pp. 571-583.

Nonaka, I., Takeuchi, H. and Takeuchi, H. (1995) 'The Knowledge-creating Company: How Japanese Companies Create the Dynamics of Innovation', Oxford University Press, pp. 284.

Oakley, P. (1997) 'High-tech NPD success through faster overseas launch', Journal of product and brand management, Vol. 6, No. 4, pp. 260-274.

Ojiako, U., Johansen, E. and Greenwood, D. (2008) 'A qualitative re-construction of project measurement criteria', Industrial Management \& Data Systems, Vol. 108, No. 3, pp. 405-417.

Oliver, N., Dostaler, I. and Dewberry, E. (2004) 'New product development benchmarks: The Japanese, North American, and UK consumer electronics industries', The Journal of High Technology Management Research, Vol. 15, No. 2, pp. 249-265.

Perttula, A. (2007) 'Challenges and Improvements of Verification and Validation Activities in High Volume Electronics Product Development', $\mathrm{PhD}$ dissertation, Tampere University of Technology, Finland. Publication 650

Pisano, G.P. and Wheelwright, S.C. (1995) 'The new logic of high-tech R\&D', Harvard Business Review, Vol. 73, No. 5, pp. 93-104.

Radeka, K. (2007) 'The Toyota Product Development System: Integrating People, Process and Technology by James M. Morgan and Jeffrey K. Liker', Journal of Product Innovation Management, Vol. 24, No. 3, pp. 276-278.

Rosemann, M. (2006) 'Potential pitfalls of process modeling: part B', Business Process Management Journal, Vol. 12, No. 3, pp. 377-384.

Rui, M., Yang, J., Hutchinson, J. and Wang, J. (2008) 'Managing knowledge for new product performance in the high technology industry', International Journal of Technology Management, Vol. 41, No. 1-2, pp. 96 - 108.

Seetharaman, A., Sreenivasan, J., Bathamenadan, R. and Sudha, R. (2007), 'The impact of just-intime on costing', International Journal of Management and Enterprise Development, Vol. 4 No. 6, pp. 635-51.

Sinha, V., Sengupta, B. and Chandra, S. (2006) 'Enabling Collaboration in Distributed Requirements Management', Software, IEEE, Vol. 23, No. 5, pp. 52-61.

Sobek, D., Ward, A. and Liker, J. (1999), 'Toyota's principles of set-based concurrent engineering', Sloan Management Review, Vol. 40, No. 2, pp. 67-83.

Su, C-T., Chen, Y-H. and Sha, D.Y-J. (2007) 'Managing product and customer knowledge in innovative new product development', International Journal of Technology Management, Vol. 39, No. 1-2, pp. $105-130$.

Ulrich, K.T. and Eppinger, S.D. (1995) 'Product Design and Development', McGraw-Hill, New York, pp. 320. 
Vassilakis, S. (1998) 'Accelerating new product development by overcoming complexity constraints', Journal of Mathematical Economics, Vol. 28, No. 3, pp. 341-373.

Veryzer, R.W. and de Mozota, B.B. (2005) 'The Impact of User-Oriented Design on New Product Development: An Examination of Fundamental Relationships', Journal of Product Innovation Management, Vol. 22, No. 2, pp. 128-143.

Ward, A., Liker, J., Cristano, J. and Sobek, D. (1995), "Second Toyota paradox: how delaying decisions can make better cars faster”, Sloan Management Review, Vol. 36, No. 3, pp. 43-61.

Wheelwright, S.C. and Clark, K.B. (1994) 'Accelerating the Design-build-test Cycle for Effective Product Development', International Marketing Review, Vol. 11, No. 1, pp. 32-46.

Yang, B., Burns, N.D. and Backhouse, C.J. (2004) 'Postponement: a review and an integrated framework', International Journal of Operations \& Production Management, Vol. 24, No. 5, pp. 468-487.

Zeidler, C., Kittl, C. and Petrovic, O. (2008) 'An integrated product development process for mobile software', International Journal of Mobile Communications, Vol. 6, No. 3, pp. 345 356. 